\title{
Concentrating on the Next Version
}

\section{Reply to the Letter by Thomas Heinemann et al. [1] to the Guest Editorial of Frank Hentschel and Rüdiger von Kummer [2]}

The German Society of Neuroradiology (DGNR) thought to stimulate the current discussion on incidental findings in brain research by publishing its position and commenting on a first draft of the guideline as proposed by the Bonn Neuroethics Working Group, Germany. The aim of the editorial of Hentschel and von Kummer on behalf of the DGNR was to enhance the quality of the discussion and provide a solid basis for the sincere criticism of the guideline as proposed so far. When writing and publishing this editorial, the revision of the guideline by Heinemann et al. was unknown. We agree with our colleagues in Bonn in now concentrating on the next version and working on the guideline for brain imaging research based on essential ethical and juridical concepts and distinctions that will become an internationally recognized standard regarding the detection and interpretation of incidental imaging findings in brain research.

\section{References}

1. Heinemann T, Hoppe C, Weber B, Elger C. Ethically appropriate handling of incidental findings in human neuroimaging research. Clin Neuroradiol 2009;19:242-3.

2. Hentschel F, von Kummer R. Response of the German Society of Neuroradiology to the guideline "Ethically appropriate reaction to incidental imaging findings in brain research", suggested by Thomas Heinemann, Institut für Wissenschaft und Ethik, and Christian Hoppe, Klinik für Epileptologie, Universität Bonn, Germany, on January 9, 2009. Clin Neuroradiol 2009;19:108-10.

Frank Hentschel, Mannheim, and Rüdiger von Kummer, Dresden, Germany 